\title{
Pulmonary involvement of Brucellosis: a report of six cases
}

\author{
Simsek F, Yildirmak MT, *Gedik H, Kantürk A, Iris EN
}

Department of Infectious Diseases and Clinical Microbiology, Ministry of Health, Okmeydaný Training and Research Hospital, Istanbul, Turkey

\begin{abstract}
Background:Pulmonary involvement of brucellosis rarely occurs due to inhalation of infected aerosol or hematogenous overspreading.

Objective The study aimed to reveal the pulmonary manifestations of brucellosis that occur rarely in Brucella infections in the context of six cases in this report.

Methods: Between 1998-2008, 82 patients with brucellosis treated and followed up at infectious diseases clinic have been retrospectively studied in relation to their clinical and laboratory findings and treatment results.

Results: Patients' ( $n=6$ ) age ranged from 48 to 59 years and they showed equal gender distribution. All patients presented with fever and cough. Radiological examination showed pneumonic patches and consolidation in two cases, bilateral glass round opacity in four cases, perivascular and peribronchial thickness increase in two cases, pleural effusion in two cases, sentri-acinar emphysematous images in one patient, and athelectasis in one patient. Blood cultures of three patients grew Brucella spp. . All patients responded to treatment containing doxycycline, rifampicin and streptomycin (for only one patient) within seven to 10 days and were treated for six weeks except for one patient for who was treated eight weeks due to hepatosplenic brucellosis.
\end{abstract}

Conclusion: Pulmonary involvement of brucellosis has good prognosis with combined antimicrobial therapy.

Key words: Brucellosis, pulmonary, manifestations

African Health Sciences 2011; 11(S1): S112 - S116

\section{Introduction}

Brucellosis is a zoonotic disease that occurs by contact with infected meat or the placenta of infected animals such as cattle, goats, camels, dogs, and pigs', or ingestion of unpasteurized milk or cheese; or by inhaling airborne agents, and rarely by transplantation and sexual course. Symptoms include weakness, fatigue, malaise, body aches, depression and anorexia $^{1-4}$. Signs and symptoms as well as the tube agglutination method, which tests for anti-Opolysaccharide antibody that titers of 1:160 or higher, are diagnostic ${ }^{5}$.

Pulmonary involvement of brucellosis rarely occurs due to inhalation of infected aerosol or hematogenous overspreading. Cough, mucopurulent sputum and flue-like symptoms are the most relevant

*Corresponding author
Dr. Habip Gedik
Department of Infectious Diseases and Clinical
Microbiology
Ministry of Health Okmeydani Training and
Research Hospital
Istanbul, Turkey
Tel: +90 5053362770
E-mail: habipgedik@yahoo.com

symptoms in pulmonary involvement of brucellosis ${ }^{10}$. Acute bronchitis, or bronchopneumonia are diagnostic aspects with radiological findings such as reticulonodular infiltration, diffuse glass round opacitiy, abscess, hilar lmyphadenopathy and pleural effusion with computerized tomography (CT) imaging of lung 5 .

This study aimed to reveal the pulmonary manifestations of brucellosis that occur rarely in Brucella infections in the context of six cases in this report.

\section{Methods}

Between 1998 and 2008, 82 patients diagnosed with brucellosis were treated and followed up at the department of infectious diseases and clinical microbiology, Ministry of Health Okmeydani Training and Research Hospital, a tertiary hospital with 1,200-bed capacity. Among these 82 patients we identified six brucellosis cases with pulmonary manifestations. Clinical, radiological and laboratory findings of these six patients were evaluated, retrospectively. The diagnosis of brucellosis was based upon evidence of contact with animals known 
to harbour the organism, or a history of ingestion of raw unpasteurized milk or its products and signs and symptoms consistent with brucellosis as described previously. The diagnosis was confirmed by a positive blood culture and/or a four-fold increase in titres, or a single serum tube agglutination test titre of 1:160 or more using Brucella abortus 99 antigen (manufactured by Pendik Veterinary Control and Research Institute, Ýstanbul, Turkey). Blood culture was implemented using manufactured bottle of Becton Dickinson (BD) Bactec automated system (New Jersey, USA). Patients with respiratory symptoms were examined with radiography of the chest and $\mathrm{CT}$ at the beginning and the end of treatment. In addition, sputum was examined with Gram and Ehrlich Ziehl Neelsen (EZN, acid-fast) stains and inoculated into aerobic and LoewensteinJensen medium (Merck Schuchardt OHG, Germany) and MGIT (Becton Dickinson, Sparks, USA). Pleural fluid aspirates were collected and sent for culture and serological examinations except for three cases, from which sufficient amounts of aspirate could not be obtained. The Mantoux test (purified protein derivative) was administered to all cases. Complete blood count and erythrocyte sedimentation rate (ESR) and $\mathrm{C}$ reactive protein (CRP) level with tests of liver and renal functions were carried out on all cases. Both drugs including doxycycline in a dose of $200 \mathrm{mg} / 24-\mathrm{h}$ and rifampicin $600 \mathrm{mg} / 24-\mathrm{h}$ were given to all cases for six weeks. Only one patient (case 4) was treated with combination of doxycycline and rifampicin for six weeks and streptomycin 1 gr/ 24-h (for two weeks).

\section{Results}

Six patients with pulmonary manifestations were evaluated. Patients' $(n=6)$ age ranged from

48 to 59 years and they showed equal gender distribution (Table-1). Possible transmission route for patients were reported as shepherd (cases1,2,3), ingestion of raw milk or products (case 2,3,4,5), and tick-bite (case 6). Crimean-Congo Hemorrhagic fever was eliminated in that patient (case 6) with serologic test. Cases 2 and 3 were married and occupied with livestock.

Table 1: Characteristics, clinical, radiological and laboratory findings of six patients with brucellosis and accompanying pulmonary manifestations

\begin{tabular}{|c|c|c|c|c|c|c|c|c|c|c|}
\hline$\overline{\text { Cases }}$ & Gender & Age & \multicolumn{2}{|c|}{$\begin{array}{l}\text { Transmission } \\
\text { route }\end{array}$} & $\begin{array}{l}\text { Leuk } \\
\left(\mathrm{x} 10^{3} / \mathrm{mm}^{3}\right)\end{array}$ & $\begin{array}{l}\text { Tromb } \\
\left(\times 10^{3} / \mathrm{mm}^{3}\right)\end{array}$ & $\begin{array}{l}\text { Hgb } \\
(g / d l)\end{array}$ & $\begin{array}{l}\mathrm{CRP} \\
(\mathrm{mg}\end{array}$ & \multicolumn{2}{|c|}{$\begin{array}{l}\text { ESR } \\
(\mathrm{mm} / \mathrm{h})\end{array}$} \\
\hline Case 1 & Female & 59 & \multicolumn{2}{|c|}{ Shepherd } & 4,3 & 160 & 10 & 65 & \multicolumn{2}{|l|}{45} \\
\hline Case 2 & Female & 50 & \multicolumn{3}{|c|}{$\begin{array}{l}\text { Shepherd and inges } 5,4 \\
\text { tionf of raw milk produts }\end{array}$} & 240 & 11,2 & 167 & \multicolumn{2}{|c|}{130} \\
\hline Case 3 & Male & 59 & \multicolumn{3}{|c|}{$\begin{array}{l}\text { Shepherd and inges- } 8,8 \\
\text { tionf of raw milk produts }\end{array}$} & 160 & 10 & 65 & \multicolumn{2}{|l|}{58} \\
\hline Case 4 & Male & 50 & \multicolumn{3}{|c|}{$\begin{array}{l}\text { Ingestion of raw milk } 2,8 \\
\text { produts }\end{array}$} & 660 & 10,1 & 181 & \multicolumn{2}{|l|}{45} \\
\hline Case 5 & Male & 50 & \multicolumn{3}{|c|}{$\begin{array}{l}\text { Ingestion of raw milk 2,1 } \\
\text { produts }\end{array}$} & 83 & 9,4 & 74 & \multicolumn{2}{|l|}{60} \\
\hline Case 6 & Female & 48 & \multicolumn{2}{|c|}{ Tick-bite } & 3,2 & 152 & 8,4 & 71 & \multicolumn{2}{|l|}{72} \\
\hline \multicolumn{11}{|c|}{ Continuation of table 1} \\
\hline Cases & $\begin{array}{l}\text { AST } \\
(\mathrm{IU} / \mathrm{L})\end{array}$ & $\begin{array}{l}\text { ALT } \\
(\mathrm{IU} / \mathrm{L})\end{array}$ & TAT & $\begin{array}{l}\text { Blood } \\
\text { culture }\end{array}$ & Treatmen & & & CT $\mathrm{f}$ & dings & Symptoms \\
\hline Case 1 & 76 & 42 & 320 & Negative & \multicolumn{3}{|c|}{ Rifampicin+doxycycline } & \multicolumn{2}{|c|}{$1,2,3,4$} & $1,2,3$ \\
\hline Case 2 & 38 & 57 & 640 & Negative & \multicolumn{3}{|c|}{ Rifampicin + doxycycline } & \multicolumn{2}{|c|}{1,5} & $3,1,5$ \\
\hline Case 3 & 48 & 82 & 2560 & Negative & \multicolumn{2}{|c|}{ Rifampicin+doxycycline } & & \multicolumn{2}{|c|}{6,7} & $3,1,2,6$ \\
\hline Case 4 & 94 & 82 & 640 & Positive & \multicolumn{3}{|c|}{$\begin{array}{l}\text { Rifampicin }+ \text { doxycycline }+ \text { strepto- } \\
\text { mycin }\end{array}$} & \multicolumn{2}{|c|}{$6,2,3$} & $3,7,8$ \\
\hline Case 5 & 65 & 54 & 640 & Positive & \multicolumn{2}{|c|}{ Rifampicin + doxycycline } & & \multicolumn{2}{|c|}{1,5} & $1,4,5$ \\
\hline Case 6 & 182 & 152 & 640 & Positive & \multicolumn{2}{|c|}{ Rifampicin + doxycycline } & & \multicolumn{2}{|c|}{1} & $3,1,7,8$ \\
\hline
\end{tabular}

CRP: Creactive protein, ESR: Erythrocyte sedimentation rate, ALT: Alanine transaminase, AST: Aspartate transaminase, TAT: Brucella tube agglutination titre, Leuk: Leukocyte, Hgb: Hemoglobin, Thromb: Thrombocyte, CT: Computerized tomography, Symptoms: 1- Cough 2- Sputum 3- Fever 4- Sweating 5-Arthralgia 6- Loosing weight 7- Fatigue 8- Myalgia. CT findings: 1- Bilateral rounding glass opacity 2- Perivascular and peribronchial thickening 3- Bilateral diffuse increased density 4- Sentriasiner emphysematous areas 5- Reticulo-nodular opacity 6- Atelectasis 
All patients presented with fever and cough. The duration of these symptoms varied from 3 weeks to 3 months (mean of 7 weeks). Other symptoms were expectoration in two (cases 1,3) and sweating in one (case 5), arthralgia in two (cases 2,5), loosing weight in one (Case 3), fatigue and malaise in two (case 4,6). Leukopenia $(<4500 / \mathrm{mm} 3)$ was in three (cases 4,5,6) and thrombocytopenia $(<150000 /$ $\left.\mathrm{mm}^{3}\right)$ was in two (Cases 4,5) and hemoglobin values ranged between 8,4 and $11,2 \mathrm{gr} / \mathrm{dl}$, CRP levels ranged between $65-181 \mathrm{mg} / \mathrm{dl}$, alanine transaminase (ALT) values were higher than normal levels $(42 \mathrm{IU} / \mathrm{ml})$ in all patients except case 2 and aspartate transaminase values were higher than upper of normal range (40 $\mathrm{IU} / \mathrm{ml}$ ) at admission for all patients. Physical examination of the chest was normal in cases 1,4,5,6; and there were and crepitations in cases 2,3. Radiological examination showed pneumonic patches and consolidation in two (cases 1,4), bilateral glass round opacity in four (cases 1,2,5,6), perivascular and peribronchial thickness increase in two (cases 1,4), pleural effusion in two (cases 3,4), sentri-acinar emphysematous images in case 1 , and athelectasis in case 3 (Figure-1). In all cases, the serological examination for Brucella revealed elevated titres in the agglutination test between 1/320 and 1/2560. Culture grew Brucella spp. from the blood of three patients (cases 4,5,6). Sputum cultures grew only commensals.

Figure 1: Computerized tomography image of patient (case 2 ) with pulmonary manifestations at admission

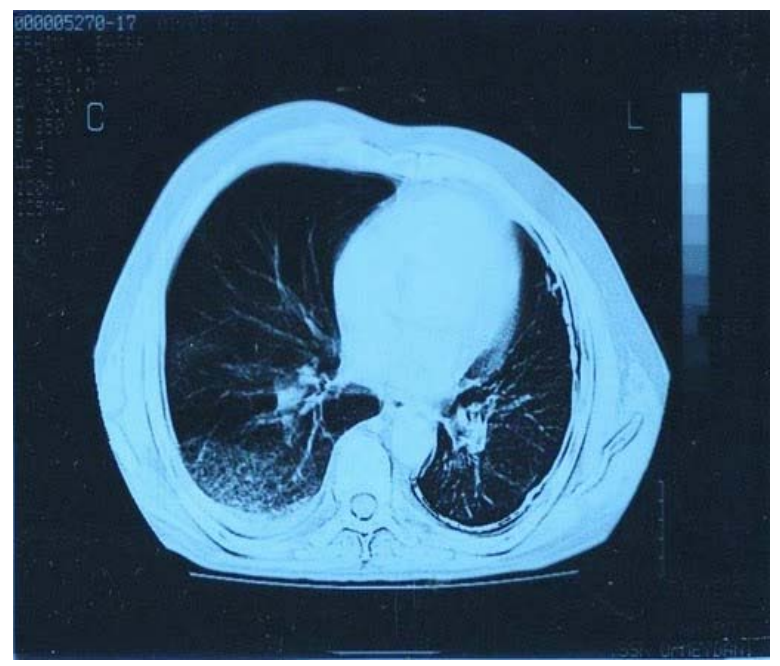

All patients responded to treatment within seven to 10 days and were treated for six weeks except for case 4 for eight weeks due to hepato-splenic brucellosis. The CRP levels and control CT images of all patients were normal at the end of treatment (Figure-2).

Figure 2: Computerized tomography image of patient (case 2) with pulmonary manifestations at the end of treatment

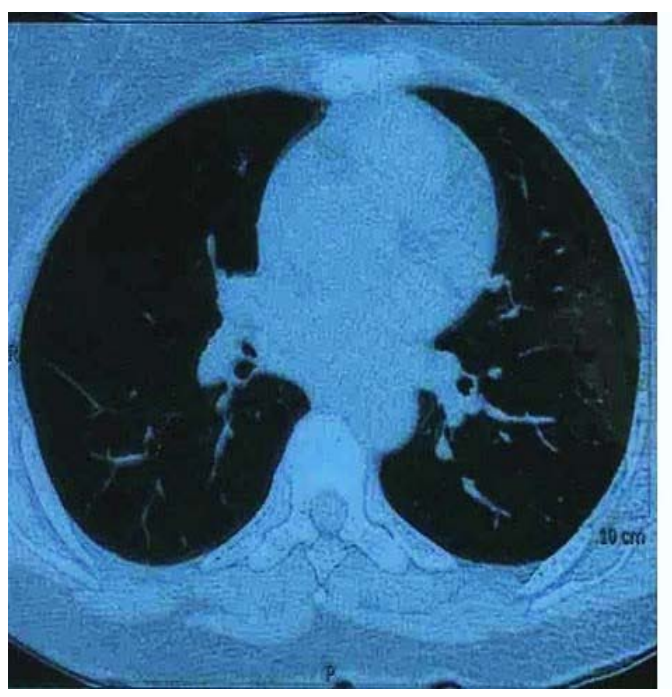

\section{Discussions}

Brucellosis is an endemic disease in Turkey, especially in certain cities where livestock is mostly kept. The disease is encountered throughout the world but is hyperendemic especially in the Mediterranean basin where Turkey is located and the Arabian peninsula, India, Mexico, middle and South American continent ${ }^{5,7,8}$.

According to the Ministry of Health in Turkey, the number of brucellosis cases were reported as 37 cases $(0,17 / 100.000)$ in 1970 when official notification was not executed appropriately, 1,177 cases $(2,34 / 100.000)$ in 1985,5003 cases $(8,69 / 100.000)$ in $1990,8,506$ cases $(13,46 / 100.000)$ in 1995,10742 cases $(15,83 / 100.000)$ in 2000,14644 cases $(20,32 / 100.000)$ in $2005,11,649$ cases $(16,16 /$ $100.000)$ in 2007 and 9,324 cases $(12,93 / 100.000)$ in $2009^{16}$. All cases had history of exposure to infected animals or their products. Ingestion of raw milk or its products, animal husbandry, and laboratorial exposure are essential risk factors for brucellosis. Animal husbandry and ingestion of raw milk and its products were reported in five of six cases in this study, except for one patient who had described only tick- bite for a possible transmission route. Patients 
with unknown transmission route history are rarely presented $^{2,3}$. Due to the fact that Brucella can invade any tissue in the body and it is endemic in Turkey, it should be considered in differential diagnosis of prolonged symptoms including fever. It seldom involves the lungs, but transmission by air is seen especially in slaughterhouse workers and laboratory staff. It was cited that pulmonary involvement of brucellosis is seen in 0,6 to 16 percent of all brucellosis cases ${ }^{10-12,17}$. Pfischner et al revealed that 37 of 228 patients $(16 \%)$ with brucellosis complained of dry non-productive cough on admission, 24 $(11 \%)$ had moderate sputum production without hemoptysis and eight (4\%) complained of chest pain of an ill-defined type which was not pleuretic in nature $^{21}$. Buchanan and his colleagues reported that $23 \%$ of 160 abattoir-associated brucellosis patients complained of cough but radiological examinations of the chest were normal ${ }^{22}$. Pure pneumonic infiltration seldom occurs in brucellosis ${ }^{13}$. Brucella could be seen in Gram preparation of sputum or cultivated from sputum culture rarely ${ }^{19,20}$.

In our study, it was not isolated from sputums of the patients. It was cited that Brucella could be isolated from blood culture between 15$80 \% 0^{5}$. It was isolated from blood cultures of three patients in our study. The pleural fluid, a common feature of pulmonary brucellosis, is characterised as lymphocytic pleocytosis, high protein concentration, increased adenosin deaminase level, and cultivation of B. melitensis ${ }^{17,19}$. It was isolated from pleural effusion in studies conducted in Balkan peninsula ${ }^{12,20}$. But thoracentesis was not executed in three of our cases with pleural effusion due to insufficient amount of pleural fluid.

Different chest radiographic abnormalities were revealed, including soft miliary mottling, parenchymal nodules, consolidation, chronic diffuse changes, hilar or paratracheal lymphadenopathy and pneumothorax ${ }^{5,10,11}$. Soft miliary mottling and pneumothorax have been described in the study of Patel et al. The high incidence of lung abnormalities was most probably due to the chronicity of the disease in that study ${ }^{18}$. In a study of Hatipodlu et al, 11 of 100 brucellosis patients were reported with pulmonary manifestations such as nodules, lobar pneumonia, paratracheal lymphadenopathy and pleural effusion ${ }^{14}$. Pneumonia due to B.melitensis was reported from Turkey as well ${ }^{15}$. Lubani et al. presented that nine cases with pulmonary symptoms and abnormal signs in the chest due to brucellosis and pulmonary manifestations, recovered with standard therapy without any relapse ${ }^{10}$. Lubani et al. also reported that in the last six years 1,100 child patients were diagnosed with brucellosis, of whom 51 (4,6\%) had the symptom cough and among them four $(0,4 \%)$ had pulmonary brucellosis ${ }^{10}$. Of our cases, $7 \%$ had pulmonary manifestations such as reticulonodular and pneumonic infiltrations and pleural effusion in CT images. Aside from inhalation, bacteremia could cause pulmonary involvement which could exhibit pulmonary signs and symptoms. The incidence of pulmonary involvement of brucellosis is therefore very low and likely to be asymptomatic.

The pathophysiology of pulmonary brucellosis is unknown. The role of aerosol inhalation is not clear as most of our patients had ingested raw milk or its products. The most probable pathophysiology is bacteremia as Brucella spp. are widely distributed through the bloodstream to various organs including lungs ${ }^{5,23}$. Brucellae that are not killed by polymorphonuclear leukocytes are ingested by macrophages, where they become localized within organs of the reticuloendothelial system (i.e. liver, spleen, bone marrow) and multiply in macrophages and monocytes ${ }^{24}$. Probably it needs the reticuloendothelial organs to multiply and also the lung does not contain any reticuloendothelial tissue, so primary pulmonary brucellosis is very rare and occurs due to distribution through the bloodstream and invading macrophages. Except for laboratory staff, airborne transmission could not be considered as another probable transmission route for patients who are shepherd and consume raw milk or its products.

Pulmonary brucellosis could be mistaken for tuberculosis and sarcoidosis, so patients with brucellosis and pulmonary manifestations should be examined for tuberculosis with EZN stain of sputum and sputum culture for tuberculosis such as Loewenstein-Jensen, MGIT etc. as in our study and also for sarcoidosis ${ }^{5,23}$. Although there are no reported cases of patients with both pulmonary brucellosis and pulmonary tuberculosis, this possibility should be kept in mind. Bihilar lymphadenopathy at stage 1 and 2, bilateral pulmonary infiltrates are diagnostic findings of sarcoidosis in chest $\mathrm{X}$-ray so those are not seen in our patients and subsequent to brucellosis therapy CT findings had disappeared ${ }^{25}$.

Treatment of brucellosis is by administration of doxycycline in a dose of $200 \mathrm{mg} / 24-\mathrm{h}$ combined with rifampicin $600 \mathrm{mg} / 24$-h for six weeks or doxycycline in a dose of $200 \mathrm{mg} / 24$-h for six weeks 
combined with rifampicin $600 \mathrm{mg} / 24-\mathrm{h}$ for six weeks and streptomycin $1 \mathrm{gr} / 24-\mathrm{h}$ for two weeks. In our study the patients were treated with doxycycline plus rifampicin for six weeks, except for one patient whose treatment was extended to two months due to hepatosplenic brucellosis. Improvement was seen in a few days after initiation of treatment in our patients. Response to treatment should be evaluated with clinical recovery and decrease in CRP level since antibody titers decrease very slowly or stay high for many months. All cases recovered clinically and radiologically at the end of treatment in our study.

\section{Conclusion}

Brucellosis, which continues to emerge as a zoonotic disease in Turkey and other countries, should be considered in unusal clinical presentations, such as pulmonary involvement without accompanying symptoms like fever, arthralgia or fatigue. Pulmonary involvement of brucellosis has good prognosis with combined antimicrobial therapy.

\section{Acknowledgement}

We certify that there is no conflict of interest with any financial organization regarding the subject discussed in the manuscript.

\section{References}

1. Doðanay M, Mepe E A. Bruselloz. Topçu AW, Söyletir G, Doðanay M eds. Enfeksiyon Hastalýklarý ve Mikrobiyolojisi. Ýstanbul:Nobel Týp kitabevleri 2008: 897-02

2. Özer S, Oltan N. Gençer S. Bruselloz: 33 olgunun deðerlendirilmesi. Klimik Dergisi 1998; 11(3): 82-4

3. Çaðatay A, Küçükoðlu S, Berk H, Eraksoy H, et al. Otuz altý bruselloz olgusunun deðerlendirilmesi. Klimike Dergisi 2002; 15(1):19-21

4. Mantur BG, Mangalgi SS, Mulimani B. Brucella melitensisa sexually transmissible agent. Lancet 1996; 347: 1763

5. Young E J. Brucella species. In: Mandell, Douglas and Bennett's Principles and Practise of Infectious Diseases. 6th ed. Philadelphia:Churcill Livingstone, 2005: 266972

6. Garcia Rodriguez JA, Garcia Sanchez JE, Munoz Bellido JL, et al. Review of pulmonary brucellosis: a case report on brucellar pulmonary empyema. Diag Microbiol Infect Dis.1989; 11:53-60

7. Black TF. Brucellosis. In:Cohen J, Powdwerly WG, eds. Infectious Diseases. 2nd ed.St. Louis:Mosby 2004: 1665-7

8. Pappas G, Papadimitriou P, Akritidis N, Cristou L, Tsianos EV. The new global map of human brucellosis. Lancet Infect Dis 2006; 6: 91
9. Yüce A, Alp-Çavup S. Türkiye’de Bruselloz: Genel Bakýp, Klimik Dergisi 2006; 19(3): 93

10. Lubani M M, Lulu A R, Araj G G, Khateeb M I, et al. Pulmonary brucellosis. QJ Med 1989; 71: 319-24

11. Kohar D K, Sharma B V, Gupta S, et al. Pulmonary manifestations in brucellosis: a report of seven cases from Bikaner(North West India). JAPI 2003; 51: 33-6

12. Pappas G, Bosilkovski N, Akritidis N, Mastora L, et al. Brucellosis and the respiratory system. CID 2003; 37: 95-9

13. Abu- Ekteish F, Kakish K. Pneumoniae as asole presentation of brucellosis Respir Med J 2001; 95: 7667

14. Hatipoðlu Ç A, Bilgin G, Tulek N, Kosar U. Pulmonary involvement in brucellosis. Journal of Infection 2005; 51(2): 116-9

15. Özturk O, Akcam Z, Sahin U, et al. Nadir bir pnömoni etkeni: Brucella melitensis:Tuberkülüz ve Toraks 2008; 56(4): 443-7

16.Türkiye Cumhuriyeti Saðlýk Bakanlýðý, Ýstatistikler,Temel Saðlýk Hizmetleri Genel Müdürlüðü Çalýpma Yýllýðý ve Zoonotik Hastalýklar Daire Bapkanlýðý, Ankara, 2009. (Available for URL: http:/ /www.saglik.gov.tr/TR/istatistik/2006/ tablo31.htm)

17. Kerem E, Diav O, Navon P, et al. Pleural fluid characteristics in pulmonary brucellosis. Thorax 1994; 49: 89-90

18. Patel PJ, Suhaibani H Al, Al-Aska A K, Kolawole T M, et al. The chest radiograph in brucellosis. Clinical Radiology 1988; 39: 39-41

19. Dikensoy O, Namiduru M, Hocaoglu S, et al. Increased Pleural Fluid Adenosine Deaminase in brucellosis Is Difficult to Differentiate from Tuberculosis. Respiration 2002; 69: 556-9

20. Gattas N, Loberant N, Rimon D. Milliary and reticulonodular pulmonary. Harefuab 1998; 135(9): 357-9

21. Pfischner WCE Jr, Ishuk KG, Neptune EM Jr, Fox SM, Farid Z, Nor el Din G. Brucellosis in Egypt: a review of experience with 228 patients. Am J Med 1957; 22: 915-929.

22. Buchanan TM, Faber LC, Feldman RA. Brucellosis in the United States 1960-1972; an abattoir associated disease. Part I. Clinical features and therapy. Medicine 1974; 53: 403-13.

23. Samra Y, Shaked Y, Hertz M, Altman G. Brucellosis: Difficulties in diagnosis and a report on 38 cases. Infection 1983; 11: 310-2.

24. Pappas G, Akritidis N, Bosilkovski M, Tsianos E. Brucellosis. N EnglJ Med 2005; 352(22): 2325-36

25. Hunninghake G W, Crystal R G. Pulmonary Sarcoidosis - A Disorder Mediated by Excess Helper T-Lymphocyte Activity at Sites of Disease Activity. NEnglJ Med 1981; 305:429-34. 